\title{
Factors Associated with Use and Types of Multiple Concurrent Care and Education Arrangements in Early Childhood in South Korea
}

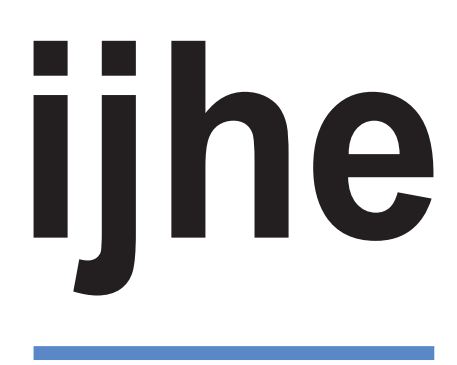

International Journal of Human Ecology

\section{Miyoung $\mathrm{An}^{*}$}

Associate Professor, School of Public Administration and Public Policy, Kookmin University

\section{Abstract}

This paper explores factors associated with multiple concurrent care and education arrangements in early childhood in South Korea. It draws on a subsample from the Korean Longitudinal Survey of Women and Families. Results show that about one-fifth of the families utilized multiple arrangements for their first preschool child. The primary non-parental option in multiplicity was nurseries or kindergartens. Home care and education options such as home study materials were found to be most prevalent secondary non-parental option, followed by services at private institution as well as relative care. Children's age, care cost, non-parental care time and time constraints were found to be positively related to the incidence of multiplicity for the first preschool child while family income and cost constraints were negatively associated. As a secondary option in the multiplicity, services at private institutions increased with children's age, care cost and when the grandparents live far from the parents' house. Home care and education utilization was found more among mothers with low degree of time constraints. Utilization of relative support decreased with the children's age and meant lower care cost and increased with mother's employment, fathers' education, family income, cost constraints and when grandparents live nearby. This paper, based on the associated factors, suggests how issues of children enrichment and constraints might be related to the multiplicity.

Keywords

Constraint, Early childhood care and education, Enrichment, Multiplicity, South Korea

\section{Introduction}

This study explores factors associated with multiple care and education arrangements in early childhood in South Korea (hereafter Korea). There have been significant structural changes which presented challenges for the government and have led to a dramatic state policy intervention in early childhood care and education. Total fertility rates have continually decreased from 1.7 in 1993 to 1.2 in 2013 (National Statistics Office, 2013a). Meanwhile, women's involvement in paid work has increased over time, growing from $42.8 \%$ in 1980 to $50 \%$ in 2013 (National Statistics Office, 1980, 2013b). In particular, the participation rates of women in their $20 \mathrm{~s}$ and $30 \mathrm{~s}$ have increased from $45.3 \%$ to $59.2 \%$ during the reference period.

\author{
Corresponding Author: \\ Miyoung An \\ School of Public Administration and \\ Public Policy, Kookmin University \\ Tel: +82-2-910-4433 \\ E-mail:myan@kookmin.ac.kr
}


The Child Care Act (CCA) was enacted in 1991 to facilitate the development of nurseries providing both care and education services for children in the years before elementary school. The number of nurseries increased by a factor of 2,216, growing from 1,919 in 1990 (Ministry of Health and Welfare, 2011) to 43,770 in 2013 (Ministry of Health and Welfare, 2013). The Infant Education Law (IEL), established in 2004, replaced the Infant Education Facilitation Law in 1982 and facilitated the development of kindergartens to provide care and education services for children from 3 years old to pre-elementary school age. The number of kindergartens increased from 3,463 in 1982 to 8,538 in 2012 (Ministry of Education, Science and Technology, 2012). The proportion of service users in either nurseries or kindergartens increased from $12.1 \%$ of preschool children aged 0-5 in 1990 to $75.2 \%$ in 2012 . By age, $32.5 \%$ of children aged $0,53 \%$ of children aged 1 , and $77 \%$ of children aged 3 received care and education services in nurseries (Ahn \& Shin, 2013) while $82.5 \%$ of children aged $3,83 \%$ of children aged 4 , and $85.3 \%$ of children aged 5 received both care and education services from nurseries and kindergartens. An (2013) have pointed out that childcare regime featured in exclusively market-centred provision. This carries significant implications for childcare and education arrangements at the individual family level as the market-centred provision works under the principle of the ability to pay for the service.

Living arrangements - namely, household composition - have transformed significantly. The proportion of families with more than five members decreased from $28.7 \%$ in 1990 to $8.1 \%$ in 2010 (National Statistics Office, 2010). However, it is important to note that the utilization of relative support has recently increased. According to the National Survey on Childcare and Education, conducted in 2004 by the Ministry of Gender Equality (multiple responses), 20.9\% used care supports provided by relatives, including grandparents and its proportion increased to $24.2 \%$ in 2009 (Ministry of Health and Welfare, 2009).

An increasing number of studies have explored multiple arrangements, mostly in the United States, in Australia and the United Kingdom (Morrissey, 2008; Neilson-Hewett, Sweller, Taylor, Harrison, \& Bowes, 2014). As for Korea, research on nonparental childcare arrangements has by and large focused on the role of grandparental care (Ko \& Hank, 2013; Lee \& Bauer, 2010,
2013) or nurseries (Ahn \& Shin, 2013); none of the studies have yet addressed multiple arrangements in the Korean context. This paper examines the prevalence of multiple arrangements of early childhood care and education as well as factors associated with the arrangements. In this study, the multiple arrangements refer to the simultaneous utilization of more than two non-parental early childcare and education options. Based on the statistical influence of the factors, we offer reasons behind the utilization of multiple arrangements. The current study uses the Korean Longitudinal Survey of Women and Families (KLoWF), conducted by the Korean Women's Development Institute (KWDI), the largest governmental think-tank for gender equality.

\section{Factors associated with multiple arrangements}

Existing research on multiple arrangements has highlighted parental preferences for children's development and constraints as prominent reasons. Exposing children to various settings and types of non-parental childcare options was believed to contribute to children's enrichment through socialization and intellectual development. Such motivations for children's enrichment might be affected by both the children's and the mothers' individual characteristics. The child's age has been shown to be significant for multiple arrangements in America and Australia - namely, the higher the child's age, the greater the chances of multiple arrangements (Capizzano \& Adams, 2000; Chen, 2013; Floge, 1985; Folk \& Yi, 1994; Harrison, 2010; Harrison, Ungerer, Smith, Zubrick, Wise, Press, Waniganayake, and the LSAC Research Consortium, 2009; Morrissey, 2008; Neilson-Hewett et al., 2014; Qu \& Wise, 2004). Mothers' characteristics, such as education and wages, indicate a higher incidence of multiple arrangements for children's enrichment (Leibowitz, Klerman, \& Waite, 1992). The degree of mothers' efforts to create stimulating environments at home increased with a higher degree of education among mothers (Chen, 2013; Claessens \& Chen, 2013).

Family income has also been considered as a source for reasoning multiple arrangements stemming from enrichment motivation. It has been hypothesized that low-income families have weak purchasing power in terms of non-parental options, particularly centre-based care, when it is weakly supported by the state while the marketization of care provision creates 
an expensive service. Therefore, low-income families tend to arrange for childcare through multiple choices that offer either cheap (Chaudry, 2004) or free options. However, some empirical evidence has indicated contradicting outcomes - namely, that no significant differences of incidence occur in multiple arrangements according to the level of household income (Morrissey, 2008). Meanwhile, high-income families were found to be more linked with multiplicity (Capizzano \& Adams, 2000; Claessens \& Chen, 2013; Harrison, 2010; Qu \& Wise, 2004). In other words, multiple arrangements have less to do with families' weak purchasing power, thereby resulting in the piecing together of cheap options that are easily assumed to carry a low quality of service and low satisfaction levels. The multiple arrangements are rather indicators of families' greater purchasing power and mothers' motivation for enriching their children, leading to an increase of incidences of multiple arrangements.

Another issue related to the multiple arrangements is constraints, manifested by availability and costs. In Australia, Goodfellow (1999) suggested that the high cost of centre-based services and the lack of places in the institutions resulted in multiple arrangements. Floge (1985) suggested that availability might intersect with children's characteristics (e.g., age): Centre-based care was more available for children older than 3 years of age, thereby increasing inclusion in multiple settings. Working mothers choose multiple arrangements to meet the care time deficits that families encounter due to long working hours (Chaudry, 2004; Chen, 2013; Flok \& Yi, 1994; Harrison, 2010; Morrissey, 2008; Qu \& Wise, 2004). Folk and Yi (1994) further demonstrated that mothers working fewer than 20 hours per week had a lower probability of utilizing multiple arrangements. When it comes to relative care, a greater number of female family members (adults or teenagers) living within the same household increased the number of incidences of utilization (Floge, 1985; Morrissey, 2008).

\section{Current study}

The current study expands the scope of analysis by including following factors. First, children's gender might serve as an important indicator to discern motivations for the children's development. Historically, Korea has featured a preference for boys over girls, contributing to gender inequalities in educational opportunities. The relationship between children's gender and the incidence of multiple arrangements can provide some sources for considering whether the prioritization of boys has declined or, when coupled with the age of children, whether young boys tend to be less likely to be exposed to multiple arrangements than girls, as mothers' direct care is perceived to be more pertinent for boys than girls. Alternatively, it might indicate that the preference for boys has declined, and the empirical evidence might indicate a correlation with more multiple arrangements for girls. Second, children's age matters, as the types of multiple arrangements might vary with the child's age. Mothers' or familial care is strongly believed to be pivotal to infants' and toddlers' development, in part due to cultural influences, whereas centre-based services, which focus more on education programs, might be more important for older preschool children aged 3 and over.

Third, we pay attention to the fathers' characteristics. The inclusion of fathers' characteristics might be interesting as American studies have shown that, when the father is the primary care provider, multiple arrangements tend to occur. We consider fathers' age, education, wages, working hour and time spent on unpaid care work. Fourth, as family level factors, we pay attention to family income which proven to be diverse in its effects on multiplicity. The issue particularly matters for the Korean case as Lee and Bauer (2013) suggested that the utilization of relative care has increasingly involved money. It is questionable whether relative care utilization carries inter-generational cash transfer in the multiplicity. Another family level factor we pay attention to is the availability of relative support. We consider the availability in term of not only the number of non-parental adults living in the same household, but also the geographical distance between adult children's households and their parents' households which we call it geographical proximity. Finally, we pay attention to the matter of constraints in terms of time and costs. Time constraint is operationalized as a gap between mother's working hours and the care time assumed by non-parental option. Cost constraint is measured by the proportion of cost of primary non-parental option against total care cost in the multiplicity.

This study addresses the following questions:

1. How prevalent are multiple arrangements and what factors are associated with them? 
2. What is the primary non-parental option within multiple arrangements and how are non-primary non-parental options distributed? What factors are associated with them?

\section{Method}

\section{Sample}

The sample for this study was drawn from KLoWF (http:// klowf.kwdi.re.kr/main.do?sLang=EN). The survey aimed to establish a longitudinal database of Korean women's lives. During their first survey in 2007, the KWDI built a sample of 9,997 women, between 19 and 64 years of age, who lived in 9,068 households across the nation. A second survey was conducted in 2009, and the third and fourth surveys were conducted in 2011 and 2012. This paper uses the third wave. Based on the 2005 Population and Housing Census, approximately 260,000 enumeration districts were used as a basic sampling frame. The primary sampling unit was selected using probability proportional to the size of systematic sampling, based on degree of urbanization, proportion of workers by industry, distribution of proportion of household by housing type, household members, and the age and gender of the household head. The survey questionnaire was designed to collect information on Korean women's economic activities, family, and leisure. It focused in particular on life events that influence women's lives, such as marriage, childbirth, childrearing, or childcare; psychological foundations of the individuals' thoughts and values; and changes over time. The third wave included 8,000 cases. The female respondents were asked to respond based not only on their own economic and family lives, but also on their family members' socio-economic attributes, including those of their husbands and children as well as those of their parents and parents-in-law. The questionnaire also included questions about attitudes on marriage, family, childbirth, childcare, and paid work.

The sub-sample was drawn from the KLoWF, where the cases were families with at least one preschool child within the household, resulting in 1,538 cases. The couples were selected as follows: Each family member was assigned a number, and cases with the number 1 (indicating a male head of the household) were selected, resulting in 1,389 cases. Individual cases with the number 2 (female spouse of family member number 1) were assumed to be wives, leaving 1,378 cases. Families without data on family income further dropped some cases, resulting in 1,362 cases. As the head of household and the spouse can be adult children's parents, families whose female spouse's age was older than 50 were further dropped. This procedure resulted in our final sample size of 1,295 families.

Table 1 provides the descriptive information of the sample under examination. Of the 1,295 families, 794 had one preschool child, 454 had two preschool children, and 47 had three preschool children. The first-born child was on average 4.36 years old, and $51.8 \%$ of the first-born children were girls. Mothers were on average 35.09 years old, and $57.4 \%$ had more than a fouryear college education. Those who reported working hours and the amount of wages were considered to be in paid employment (14.5\% of mothers). On average, they worked 7.91 hours per day and earned an average wage of KRW 1,903,600 per month. Fathers were found to be 37.7 years old on average, and $64 \%$ had a four-year college education or higher. Fathers who provided information on working hours and wages were considered to be in paid employment $(80.9 \%)$. They worked an average of 9.11 hours per day, earning an average wage of KRW 3,049,500 per month. The average time fathers spent on unpaid care work was estimated at 55.4 minutes daily in a typical week. Couples' average wages amounted to KRW 2,752,400 per month. Families' annual income amounted to an average of KRW 39,142,300. Average monthly childcare costs for the first child were KRW 237,700. Total nonparental care time was estimated to be 6.8 hours on average. Adult families who lived within 30 minutes by car from the grandparents' house accounted for $44.8 \%$. The costs of nurseries/kindergartens measured as a proportion of monthly family income was 7.04\%. The proportion of families in which the mother's working hours exceeded the care time in nurseries/kindergartens was $8 \%$.

\section{Independent variables}

The children's age was used as a ratio variable. Children's gender was coded as 0 for boys and 1 for girls. Mothers' age, working hours, and wages were analysed as ratio-level variables. Apropos of education, those with less than a four-year collegelevel education were coded as 0 ; those with more than a fouryear college-level education were coded as 1 . Those who had 
Table 1. Sub-sample characteristics of $\operatorname{KLoWF}(\mathrm{N}=1,295)$

\begin{tabular}{|c|c|c|c|}
\hline & $\mathrm{n}(\%)$ & Mean & S.D. \\
\hline \multicolumn{4}{|l|}{ Children's characteristics } \\
\hline \multicolumn{4}{|l|}{ Number of preschool children } \\
\hline One & $794(61.3)$ & & \\
\hline Two & $454(35.1)$ & & \\
\hline Three & $47(3.6)$ & & \\
\hline Age (first child) & & 4.36 & 1.50 \\
\hline Gender $(\%$, girl, first child $)$ & $671(51.8)$ & & \\
\hline \multicolumn{4}{|l|}{ Mothers' characteristics } \\
\hline Age & & 35.09 & 3.96 \\
\hline Education ( $\%$, above 4 years' college) & $743(57.4)$ & & \\
\hline In employment & $188(14.5)$ & & \\
\hline Working hours (per day) & & 7.91 & 1.65 \\
\hline Wage (10,000 KRW, per month) & & 190.36 & 96.80 \\
\hline \multicolumn{4}{|l|}{ Fathers' characteristics } \\
\hline Age & & 37.70 & 4.32 \\
\hline Education ( $\%$, above 4 years' college) & $834(64.4)$ & & \\
\hline In employment & $1,048(80.9)$ & & \\
\hline Working hours (per day) & & 9.11 & 1.53 \\
\hline Wage (10,000 KRW, per month) & & 304.95 & 275.77 \\
\hline Time spent on unpaid care work (minutes per day) & & 55.40 & 79.09 \\
\hline \multicolumn{4}{|l|}{ Family characteristics } \\
\hline Couple's monthly wage (10,000 KRW) & & 275.24 & 305.12 \\
\hline Family's annual income (10,000 KRW) & & $3,914.23$ & $1,812.75$ \\
\hline Childcare cost (first child) $(10,000 \mathrm{KRW})$ & & 23.77 & 19.23 \\
\hline Non-parental care time (hours, per day) & & 6.83 & 2.27 \\
\hline Geographical distance to grandparents' house ( $\%$, less than 30 minutes by car) & $561(44.8)$ & & \\
\hline Costs of nurseries/kindergartens as proportion of monthly family income & & 7.04 & 9.57 \\
\hline $\begin{array}{l}\text { Time of nurseries/kindergartens as proportion of mother's working hours } \\
(\%, \text { proportion more than } 100 \% \text { of working hours) }\end{array}$ & $82(8.0)$ & & \\
\hline
\end{tabular}

information on working hours and wages were coded as 1 to indicate that they were in paid employment while others were coded as 0 to indicate they were not. Mothers' and fathers' time spent on unpaid care work was operationalized as a ratio variable, and we used the average amount of time per day for a week.

Family annual income was included as a ratio variable. In addition, we included the parents' joint wage as wage is a part of income. The geographical distance to grandparents' house was operationalized as follows: The KLoWF collected information on the distance between adult children and their parents' household as the duration of the trip by car. Those who lived close by (i.e., requiring fewer than 30 minutes of travel by car) were coded as
0 while those who lived further away (i.e., requiring more than 30 minutes by car) were coded as 1 . We coded 1 for cases with working mothers whose working hours exceeded the primary care option's daily care service time and 0 for cases whose mothers' working hours was equal to or less than the care time of the primary non-parental care option. If the proportion of primary nonparental option is large, cost constraints is high.

\section{Dependent variables}

The KLoWF collected data on the utilization of relative care, nurseries, kindergartens, private care and educational institutions, and private care and teaching arrangements at home as well as paid 
International Journal of Human Ecology

Table 2. Types of non-parental options

\begin{tabular}{lll}
\hline & \multicolumn{1}{c}{ Types } & \multicolumn{1}{c}{ Sub-types } \\
\hline Formal & Nurseries/kindergartens & Both public and private \\
& Private care and education facilities & Arts or math and English education service \\
Informal & Home care and education & Visiting home teacher, home care and education materials \\
& Paid personal carers & Nannies \\
\hline & Relatives & Grandparents, other relatives \\
\hline
\end{tabular}

Table 3. Distribution of number of non-parental options by child birth order

\begin{tabular}{cccc}
\hline Number of non-parental care option & First preschool child & Second preschool child & Third preschool child \\
\hline 0 & $177(13.7)$ & $188(35.6)$ & $31(66.0)$ \\
1 & $869(67.1)$ & $293(55.5)$ & $10(21.3)$ \\
2 & $210(16.2)$ & $40(7.6)$ & $3(6.4)$ \\
3 & $37(2.9)$ & $7(1.3)$ & $2(4.3)$ \\
4 & $2(0.2)$ & $528(100.0)$ & $1(2.1)$ \\
Total & $1,295(100.0)$ & & $47(100.0)$ \\
\hline
\end{tabular}

personal care arrangements, such as nannies. We divided these into five categories. We regarded 1) nurseries and kindergartens as one of the formal options. We regarded 2) services at private institutions to be another centre-based care (in Korean they are called Hakwons) which also provided formal services. We included this type in the analysis although the institutions mainly provide education programs not least because nurseries in Korea provide both care and education services. The three informal care options include 3) relative care, 4) private care and teaching arrangements at home, and 5) nannies. In this study, multiple arrangements entail the utilization of more than two non-parental options displayed in Table 2. The multiple arrangements can be composed of as a combination of formal care and education such as nurseries, kindergartens, and private educational institutions. Alternatively, parents can choose to utilize more than two informal types of care and education options, or they could choose a combination of more than two of both informal and formal care and education options.

\section{Analytical plan}

We first ran a descriptive analysis to discern the distribution of multiple arrangements. This provided us with information on the prevalence of families with no non-parental childcare and education options, with one option, with two options, and with more than three options. We then conduct logistic regression to discern factors associated with the incidence of multiple arrangements. Model 1 and Model 2 examine the factors associated with the incidence of multiple arrangements for the first and second child, respectively. In this study, we focus on primary and non-primary options in the multiple arrangements. Primary and secondary option is determined by non-parental care time, considering the longest one as a primary option. We explore factors associated with the utilization of different non-primary non-parental options in logistic regression models 3,4 and 5 .

\section{Results}

\section{Prevalence of multiple arrangements}

Table 3 shows the distribution of the number of non-parental early childhood care and education options utilized by families with preschool children. Approximately 14\% of families did not use any non-parental childcare and education options for the first child. Families with only one non-parental care and education option accounted for $67.1 \%$ of total families. Families with multiple arrangements for the first child accounted for $19.2 \%$ of all 1,295 families. Apropos of the second child, 35.6\% of families did not utilize any type of non-parental options while $55.5 \%$ utilized 
Table 4. Predictors associated with multiple childcare arrangements

\begin{tabular}{|c|c|c|c|c|c|c|}
\hline & \multicolumn{3}{|c|}{ Model 1 First child } & \multicolumn{3}{|c|}{ Model 2 Second child } \\
\hline & $B$ & $S E$ & OR & B & $S E$ & OR \\
\hline \multicolumn{7}{|l|}{ Children's characteristics } \\
\hline Age & $.41^{* *}$ & .12 & 1.50 & .54 & .33 & 1.71 \\
\hline Sex & .28 & .26 & 1.32 & -.12 & .62 & .89 \\
\hline \multicolumn{7}{|l|}{ Mothers' characteristics } \\
\hline Age & -.03 & .05 & .98 & -.13 & .10 & .88 \\
\hline Education & -.40 & .31 & .67 & -.74 & .86 & .48 \\
\hline Employment & 1.73 & 1.84 & 5.67 & 141.36 & 101265.14 & $2.460 \mathrm{E}+061$ \\
\hline Working hour & -.37 & .25 & .69 & -17.78 & 12658.14 & .00 \\
\hline Wage & -.001 & .004 & 1.00 & -.01 & .01 & .99 \\
\hline \multicolumn{7}{|l|}{ Fathers' characteristics } \\
\hline Age & -.01 & .04 & .99 & .07 & .11 & 1.07 \\
\hline Education & .33 & .33 & 1.39 & .06 & .89 & 1.06 \\
\hline Working hour & .07 & .09 & 1.07 & -.27 & .21 & .76 \\
\hline Wage & .001 & .002 & 1.00 & .002 & .01 & 1.002 \\
\hline Unpaid care time & .002 & .002 & 1.00 & $.01^{*}$ & .003 & 1.01 \\
\hline \multicolumn{7}{|l|}{ Family characteristics } \\
\hline Couple's wage & -.001 & .002 & 1.00 & -.001 & .01 & 1.00 \\
\hline Family income & $-.02^{* * *}$ & .002 & .99 & -.01 & .01 & .99 \\
\hline Care cost & $.29^{* * * *}$ & .03 & 1.34 & $.19^{* * * *}$ & .05 & 1.20 \\
\hline Non-parental care time & $.99^{* * * *}$ & .10 & 2.68 & $.89^{* * *}$ & .19 & 2.43 \\
\hline Cost constraint & $-.80^{* * *}$ & .09 & .45 & $-.57^{* *}$ & .17 & .56 \\
\hline Time constraint & $1.91^{*}$ & .79 & 6.78 & 1.91 & 2.06 & 6.77 \\
\hline Distance to grandparents' house & -.35 & .26 & .70 & -1.31 & .68 & .27 \\
\hline Constant & $-7.01^{* * *}$ & 1.92 & & -4.15 & 4.75 & \\
\hline Cox \& Snell $R^{2}$ & & $421.68^{* * *}$ & & & $83.34^{* * *}$ & \\
\hline Nagelkerke $R^{2}$ & & .44 & & & .34 & \\
\hline$-2 \operatorname{LL}\left(\chi^{2}\right)$ & & .66 & & & .62 & \\
\hline
\end{tabular}

OR is odd ratio.

$" p<.05, " * * 0.01, " * * * 001$.

one and multiplicity was $9 \%$.

Table 4 shows that the child's age exerted a positive influence for the first child. The older children are, the higher the chances are of using more than two non-parental childcare options $(B=.41$, $S E=.12, p<.01)$. None of the mothers' or fathers' characteristics were found to be significant. Interestingly, family income was shown to decrease the probability of multiple arrangements $(B=-.02$, $S E=0.002, p<.001)$. Childcare costs are significantly and positively related to multiple arrangements as they increased the chances of using multiple childcare arrangements by 0.34 times. In addition, multiple childcare arrangements meant an increase in the amount of non-parental care time $(B=.99, S E=.10, p<001)$.
Table 5. Prevalence of primary and non-primary non-parental care in multiple arrangements.

\begin{tabular}{llrc}
\hline & & $\begin{array}{r}\text { First } \\
\text { child }\end{array}$ & $\begin{array}{c}\text { Second } \\
\text { child }\end{array}$ \\
\hline Primary & Nurseries or kindergartens & 233 & 45 \\
Non-primary & Private care and education facilities & 82 & 14 \\
& Nannies & 3 & - \\
& Home care and education & 123 & 21 \\
& Relatives & 67 & 21 \\
\hline
\end{tabular}

Our study also identified the significant influence of burdens generated by the cost of the primary option. Of the 1,295 families, $1,026(79.2 \%)$ utilized service at nurseries or kindergartens for the first child. Of the 501 families with more than two preschool 
Table 6. Predictors for non-primary non-parental care options of multiple childcare arrangements.

\begin{tabular}{|c|c|c|c|c|c|c|c|c|c|}
\hline & \multicolumn{3}{|c|}{$\begin{array}{l}\text { Model } 3 \text { Private care and education } \\
\text { facilities }(\mathrm{n}=82)\end{array}$} & \multicolumn{3}{|c|}{$\begin{array}{l}\text { Model } 4 \text { Home care and } \\
\text { education }(n=123)\end{array}$} & \multicolumn{3}{|c|}{$\begin{array}{l}\text { Model } 5 \text { Relatives } \\
\qquad(\mathrm{n}=67)\end{array}$} \\
\hline & $B$ & $S E$ & OR & $B$ & $S E$ & OR & $B$ & $S E$ & OR \\
\hline \multicolumn{10}{|l|}{ Children's characteristics } \\
\hline Age & $1.30^{* * * *}$ & .29 & 3.66 & .11 & .19 & 1.12 & $-1.45^{* * *}$ & .37 & .24 \\
\hline Sex & .06 & .39 & 1.06 & .11 & .35 & 1.12 & -1.16 & .68 & .31 \\
\hline \multicolumn{10}{|l|}{ Mothers' characteristics } \\
\hline Age & -.04 & .08 & .97 & -.04 & .06 & .96 & -.15 & .11 & .87 \\
\hline Education & -.03 & .52 & .98 & .25 & .43 & 1.29 & -.51 & .80 & .60 \\
\hline Employment & -.83 & 3.33 & .44 & -4.19 & 2.68 & .02 & $7.85^{*}$ & 3.32 & 2565.58 \\
\hline Working hour & .41 & .42 & 1.51 & .54 & .35 & 1.72 & 1.21 & .52 & .30 \\
\hline Wage & -.02 & .01 & .99 & -.002 & .01 & 1.00 & .004 & .01 & 1.00 \\
\hline \multicolumn{10}{|l|}{ Fathers' characteristics } \\
\hline Age & .01 & .07 & 1.01 & -.01 & .06 & .99 & .18 & .10 & 1.20 \\
\hline Education & -.39 & .54 & .68 & .09 & .46 & 1.10 & $2.31^{*}$ & .98 & 10.06 \\
\hline Working hour & -.13 & .13 & .88 & .04 & .11 & 1.04 & .07 & .18 & 1.07 \\
\hline Wage & -.003 & .003 & 1.00 & -.002 & .002 & .99 & -.003 & .004 & 1.00 \\
\hline Unpaid care time & .00 & .003 & 1.00 & .00 & .002 & 1.00 & -.001 & .003 & 1.00 \\
\hline \multicolumn{10}{|l|}{ Family characteristics } \\
\hline Couple's wage & .003 & .002 & 1.003 & .001 & .002 & 1.00 & .000 & .004 & 1.00 \\
\hline Family income & -.001 & .002 & 1.00 & .001 & .002 & 1.00 & $.01^{* * *}$ & .004 & 1.01 \\
\hline Care cost & $.04^{* *}$ & .01 & 1.05 & .01 & .01 & 1.01 & $-.08^{* * *}$ & .02 & .92 \\
\hline Non-parental care time & -.18 & .10 & .84 & $-.33^{* * *}$ & .09 & .72 & $1.47^{* * *}$ & .29 & 4.34 \\
\hline Cost constraint & -.04 & .06 & .96 & -.04 & .06 & .96 & $.30^{* *}$ & .11 & 1.36 \\
\hline Time constraint & .13 & 1.21 & 1.14 & $-2.42 *$ & 1.04 & .09 & 2.33 & 1.32 & 10.28 \\
\hline Distance to grandparents' house & $1.25^{* *}$ & .43 & 3.51 & .16 & .36 & 1.17 & $-1.82^{* *}$ & .70 & .16 \\
\hline Constant & $-5.77^{*}$ & 3.00 & & 2.36 & 3.24 & & $-10.11 *$ & 4.80 & \\
\hline Cox \& Snell $R^{2}$ & & $172.90^{* * * *}$ & & & $217.97^{* * * *}$ & & & $87.77^{* * * *}$ & \\
\hline Nagelkerke $R^{2}$ & & .31 & & & .22 & & & .54 & \\
\hline$-2 \mathrm{LL}(\chi 2)$ & & .43 & & & .29 & & & .76 & \\
\hline
\end{tabular}

$\mathrm{OR}$ is odd ratio.

${ }^{*} p<.05,{ }^{* *} p<.01,{ }^{* * *} p<.001$.

children, 278 (55.7\%) use the services. Time at nurseries/ kindergartens was the longest and thereby we consider it as the primary non-parental option. The relationship between the cost of the primary non-parental option and multiple arrangements is negative, suggesting that chances for multiple arrangements increase when the cost of the primary option is low $(B=-.80$, $S E=.09, p<.001)$. Multiple arrangements also correlate with time constraints: Longer hours of mothers' work than service time at nurseries/kindergartens increased the incidences of multiple arrangements $(B=1.91, S E=.79, p<.05)$.

As for the second child (Model 2), four factors were found to be influential. First, fathers' involvement in unpaid care work increased the incidences of multiple arrangements $(B=.01$, $S E=.003, p<.05)$. As with the first child, childcare costs and non-parental care time were positively associated with multiple arrangements. The second preschool child was also more likely to be exposed to multiple arrangements when the primary nonparental option was not costly $(B=-.57, S E=.17, p<.01)$. 
Prevalence of non-primary non-parental options in multiple arrangements and associated factors

This section provides the results of the descriptive analysis on the types of non-parental options in the multiple arrangements for the first and second child. We also ran logistic regressions to discern factors associated with the utilization of secondary or tertiary non-parental options. We found that these regression results are not significant for the second child; thus, we present the results for the first child only.

Table 5 shows the distribution of non-parental option utilization for the first and second child. Among the families with multiple arrangements, 233 of 249 families (93.6\%) and 45 of 47 families $(95.7 \%)$ used the nurseries/kindergartens as the primary nonparental care option for the first and second children, respectively. Of the 233 families who utilized centre-based care as the primary care option for the first child, 82 families utilized other private and educational facilities, 3 families hired nannies, 123 families utilized home care and education, and 67 families utilized relative care. Of the 45 families who utilized multiple arrangements with the centrebased service as a primary option for the second preschool child, 14 families utilized institution-based private care and education services while 21 families utilized home care and education and relative care as their non-primary options.

Table 6 shows the logistic regression results for the factors associated with different types of non-primary non-parental options. As the number of cases for families with nannies was small, the regression could not be run. The regression output (Model 3) shows that the children's age increased the chances of using services at private institutions $(B=1.30, S E=.29, p<.001)$. The utilization of such option meant increasing childcare costs $(B=.04$, $S E=.01, p<.01)$. Interestingly, geographical distance to the adult parents' house was proven to be important $(B=1.25, S E=.43, p<.01)$ that living far from the grandparents' house predicts the use of the option in addition to nurseries or kindergartens, the primary option.

When it comes to the utilization of home care and education (Model 4), non-parental care time explains the utilization in a negative relationship $(B=-.33, S E=.09, p<.001)$. In addition, the use of the option is negatively associated with time constraints. In other words, mothers with less working time tended to use the home care and education option. Finally, for relative care (Model
5), children's age is negatively associated, as a younger child has a higher chance of receiving relative care $(B=-1.45, S E=.37, p<.001)$. Mother's employment increased the chances of using relative care as a non-primary non-parental option $(B=7.85, S E=3.32, p<.05)$. Father's education increased the use of relative care $(B=2.31$, $S E=.98, p<.05)$. Families with a higher income tended to utilize relative care $(B=.01, S E=.004, p<.01)$. Relative care utilization as a non-primary non-parental option means low childcare $\operatorname{cost}(B=-.08$, $S E=.02, p<.001)$. In addition, the greater the cost of the primary option, the greater the chance there was of relying on relative care as non-primary non-parental option $(B=.30, S E=.11, p<.01)$. Finally, living close to the grandparents increased the degree of utilization of relative care $(B=-1.82, S E=.70, p<.01)$.

\section{Discussions}

\section{Shedding light on reasons behind multiple arrangements}

The current study found a number of factors associated with the multiple arrangements in Korea, as in the United States and Australia. As in other studies (Capizzano \& Adams, 2000; Chen, 2013; Floge, 1985; Folk \& Yi, 1994; Harrison, 2010; Harrison et al., 2009; Morrissey, 2008; Neilson-Hewett et al., 2014; Qu \& Wise, 2004), the child's age mattered. Each year of the child's age was predicted to increase the incidence of multiple arrangements for the first preschool child. The gender of the child was found to exert no influence on the multiplicity, as was the case in America (Chen, 2013; NICHD ECCRN, 2001). The multiple arrangements in Korea were also a matter of cost in that families with higher childcare costs had positive influence.

At the same time, we have offered interesting findings. First, a child's age differentiated the types of non-primary non-parental option. Older preschool children had a greater chance of receiving care and educational services at private institutional settings while they were less likely to be exposed to relative care. Mothers' paid employment was not found to be influential for multiple settings (see Table 5) but was significant for the utilization of relative care as a non-primary non-parental option (see Table 6). This study also found that fathers' education was positively related to relative care utilization as a supplement to the primary option - that is, nurseries or kindergartens (see Table 6). 
Second, this study found various factors associated with the multiple arrangements for the second preschool child. The age of children was no longer relevant for multiplicity. Multiple arrangements for the second preschool child often meant relatively lower cost. Fathers' involvement in unpaid care work increased the chances for the multiplicity. These can be read that Korean families invest more in the first child by utilizing various non-parental options and are more likely to involve the father with the second child, which is free, as the multiple arrangements were also driven by the degree of financial burden caused by the primary childcare option - namely, centre-based care.

Third, the influence of family income is interesting. It has shown a negative relationship with multiple arrangements but it correlates with childcare cost. Put differently, multiple arrangements are costly in Korea, as in other countries, but they do not necessarily imply that families with multiple arrangements have more purchasing power than families with non-multiple arrangements (see Table 5). This peculiarity is evident in the utilization of relative care as secondary option (see Table 6): High-income families tended to rely on relative care as secondary option, which was proven to be a matter of non-parental care time, not a matter of cost. In other words, when families utilized relative care, it increased total non-parental care time, but did not change childcare costs. Our study provided evidence that it does not involve money exchanges when the relative care is utilized as a supplementary care option in addition to nurseries/kindergartens.

Fourth, our study demonstrated that multiple arrangements are a matter of not only cost constraints, but also time constraints. By operationalizing the differences between mothers' working hours and the care time of non-parental service in either nurseries or kindergartens, this study specified the meaning of time constraints in a context-specific manner for Korea. Given the fact that the majority of families (two-thirds) with preschool children used either nurseries or kindergartens we detailed that care time in those institutions are not still meeting the care time demand of working mothers. This carries significant implications for future childcare policy reforms in that the childcare services at those institutions need to extend its service time to meet the demand.

Finally, this study suggests that living arrangements between adult children and their parents in terms of geographical distance are significant. This factor was proven not to be influential in terms of whether or not families organize childcare and education in multiple settings (see Table 5). Rather, it is associated with the use of services at private institutions. It is also related to the utilization of relative care as a non-primary non-parental option (see Table 6). It is important to note that the degree of influences on the utilization of relative care is higher for the geographical distance factor than for other factors, such as financial capacity. That is, living far from grandparents' house reduces the chances of utilizing relative care as a non-primary non-parental option by a chance of 0.84 , whereas family income increased it by a chance of 0.01 .

What can we infer from the results on the choices of multiple arrangements in terms of the reasons behind parental choices between preferences and constraints? It seems that the preference for children's development is relevant for Korea's multiple arrangements as the results indicate that multiple arrangements increase with the children's age. In specific, the enrichment has different meanings for preschool children by age group. For younger preschool children, multiple arrangements involve relative care; for older preschool children, they include services at private institutions, which largely focus on education.

This study also found that fathers' and mothers' characteristics work as sources for different reasons. Highly educated men are likely to prefer to utilize relative care as a non-primary nonparental option when it comes to multiple arrangements, perhaps as a way to increase stable and reliable care arrangements for their young preschool children. Mothers' characteristics speak of constraints more. Being in paid employment and working longer hours created time constraints, thereby resulting in multiple arrangements. In addition to the time constraints, this study found that Korean families with preschool children are significantly concerned with the cost of the primary option in the process of making multiple arrangements. In other words, the financial burden created by the utilization of nurseries or kindergartens limited the chances of utilizing other types of non-parental options. All in all, Korean families with multiple arrangements are shaped by both parental preferences for children's development and time and cost constraints, as framed by children's, parents', and family characteristics. 


\section{Limitations and suggestions for further research}

This paper bears some limitations which can be resolved in future research. First, it might be useful to include the number of children and to see how and to what extent caring for elementary school-aged and older children influences the caring in the childcare arrangements for preschool children. Second, it might be useful to employ qualitative research in order to discern how the motivations of parental preferences for children's development and constraints interact with each other to influence the multiple arrangements. Finally, it might be worth investigating if the geographical distance to adult parents' houses would have different effects depending on which side of the family the grandparents are from.

\section{Conclusions}

This study has explored factors associated with multiple arrangements among families with at least one preschool child in Korea. This study found that about one-fifth of families utilized multiple arrangements for the first preschool child. The associated factors included the children's and the families' characteristics, such as the children's age, families' incomes, and time and cost constraints. We found that nurseries or kindergartens are the primary non-parental options in multiplicity, and home care and education options were the most prevalent non-primary nonparental options, followed by services at private institutions and relatives. Factors associated varied for the different non-primary non-parental options. Although some findings are consistent with studies in the United States and Australia, we found interesting results. First, older preschool children have more chances of receiving care and education services at private institutional settings, but are less likely to be exposed to relative care as the nonprimary non-parental care option. Second, multiple arrangements involve time and cost constraints. Third, multiple arrangements are costly in Korea, as they are in other countries, but this does not necessarily imply that families with multiple arrangements have more purchasing power than families with non-multiple arrangements. Finally, living arrangements, measured in terms of the geographical distances, are important for understanding the utilization of relative care as a non-primary non-parental care option in the multiplicity. We suggest that both parental preferences and constraints are simultaneously important. In childcare policy reforms, it is left for discussion whether such multiplicity is better for children's development and, if so, how policy reforms can help parents meet the preferences reducing constraints.

\section{References}

Ahn, J., \& Shin, N. (2013). The use of child care center for infants of dual-working families in Korea. Children and Youth Services Review, 35(9), 1510-1519.

An, M. (2013). Childcare expansions in East Asia: Changing shape of the institutional configurations in Japan and South Korea, Asian Social Work and Social Policy, 7(1), 28-43.

Capizzano, J., \& Adams, G. (2000). The number of child care arrangements used by children under five: Variation across states, Series B, No. B-12, The Urban Institute, Washington.

Chaudry, A. (2004). Putting children first: How low-wage working mothers manage child care. New York: Russell Sage Foundation.

Chen, J. J. (2013). Multiple childcare arrangements and health outcomes in early childhood. Maternal Child Health Journal, 17(3), 448-455.

Classens, A. \& Chen, J. J. (2013). Multiple child care arrangements and child wellbeing: Early care experiences in Australia. Early Childhood Research Quarterly, 28(1), 49-61.

Floge, L. (1985). The dynamics of child care use and some implications for women's employment. Journal of Marriage and the Family, 47(1), 143-154.

Flok, K. F., \& Yi, Y. (1994). Piecing together child care with multiple arrangements: Crazy quilt or preferred pattern for employed parents of preschool children. Journal of Marriage the Family, 56(3), 669680.

Goodfellow, J. (1999). Multicare arrangement patchworks: The multiple use of formal and informal care in NSW. Report for New South Wales Department of Community Services, Office of Child Care, Sydney.

Harrison, L. J. (2010). Children's experiences of child care. LSAC Annual Statistical Report. Melbourne, Australia: Australian Institute of Family Studies.

Harrison, L. J., Ungerer, J., Smith., G., Zubrick, S., Wise, S., Press, 
F., Waniganayake, M., and The LSAC Research Consortium. (2009). Child care and early education in Australia - The Longitudinal Study of Australian Children (Social Policy Research Paper No. 40). Canberra, Australia: Department of Families, Housing, Community Services and Indigenous Affairs, Commonwealth of Australia.

Ko, P-C., \& Hank, K. (2013). Grandparents caring for grandchildren in China and Korea: findings from CHARLS and KLoSA. Journal of Gerontology, Series B: Psychological Sciences and Social Science. doi:10.1093/geronb/gbt129.

Lee, J., \& Bauer, J. (2013). Motivations for providing and utilizing child care by grandmothers in South Korea. Journal of Marriage and Family, 75(2), 381-402.

Leibowitz, A., Klerman, J. A., \& Waite, L. J. (1992). Employment of new mothers and child care choice: Differences by children's age, The Journal of Human Resources, 27(1), 112-133.

Morrissey, T. W. (2008). Familial factors associated with the use of multiple child-care arrangements. Journal of Marriage and Family, 70(2), 549-563.

Ministry of Education, Science and Technology and Korean Educational Development Institute (2012). Yearbook of education statistics. Seoul: MEST, KEDI.

Ministry of Health and Welfare (2009). National childcare surveyhousehold report. Seoul: MHW.
Ministry of Health and Welfare (2011). Childcare statistics. Seoul: MHW.

Ministry of Health and Welfare (2013). Childcare statistics. Seoul: MHW.

National Institute of Child Health and Human Development Early Child Care Research Network. (2001). Non-maternal care and family factors in early development: An overview of the NICHD study of early child care. Journal of Applied Developmental Psychology, 22(5), 457-492.

National Statistics Office. (1980). Labor statistics yearbook. Seoul: NSO.

National Statistics Office. (2010). Population trends. Seoul: NSO.

National Statistics Office. (2013a). Population survey. Seoul: NSO.

National Statistics Office. (2013b). Labor statistics yearbook. Seoul: NSO.

Neilson-Hewett, C., Sweller, N., Taylor, A., Harrison, L., \& Bowes, J. (2014). Family, child and location factors and parents' reasons for multiple concurrent childcare arrangements in the years before school in Australia. Early Childhood Research Quarterly, 29(1), 52-63.

Qu, L., \& Wise, S. (2004). Multiple childcare arrangements in Australia. Family Matters, 69, 56-61. 